\title{
The Moral Significance of Capturing Micro-inequities in Hospital Settings
}

\section{Article Published as}

Subramani, S., 2018. The moral significance of capturing micro-inequities in hospital settings. Social Science \& Medicine, 209, pp.136-144. https://doi.org/10.1016/j.socscimed.2018.05.036

This is a PDF file of an preprint version of the manuscript which has been accepted for publication. The final manuscript has undergone peer-review process, copyediting and typesetting. Please refer to the paper along with supplementary files available and cite the version of peer-reviewed manuscript available at https://www.sciencedirect.com/science/article/pii/S027795361830279X

\begin{abstract}
This paper illustrates and reflects on subtle micro-level events and practices that sustain and reproduce unequal relationships in healthcare encounters, and draws attention to their moral significance in two hospitals in the south Indian city of Chennai. Based on observational data and in-depth interviews with 16 surgeons, 11 nurses, and 36 patients and their family members between February 2016 and July 2017, it reveals how both victims and perpetrators normalize instances of micro-inequities, often failing to recognize or acknowledge them. The findings illustrate how the prevalence of micro-inequities varies between different medical institutions, and suggest that while subtle in nature, their effect raises concerns regarding dignity and respect for patients and family members. Drawing on existing philosophical analyses of micro-inequities, the study concludes that their production in hospital settings creates an institutional ethos that disdains and marginalizes patients and their family members. Further, it negatively influences the patient/family-doctor relationship and functions as a barrier to reflective patient-centered care.
\end{abstract}

Key Words: Micro-Inequities, Doctor-patient Relationship, Power Asymmetry, Subtle Discrimination, Qualitative Analysis 


\section{Introduction}

The significance of effective communication between doctors and patients has been a key area of discussion in various academic fields of enquiry such as medical sociology, medical anthropology, health management, medical ethics, and so on. Various studies that explored the doctor-patient relationship have concluded that effective communication leads to better health care outcomes, increased patient satisfaction, and improved patient safety (Bensing, 1991; Ramsden, 1975; Cordella, 2004; Duffy et al., 2004; Essers et al., 2013; Epstein, 2013; Griffin et al., 2004; Stewart et al., 1999). The power asymmetry in the relationship between the doctor and the patient is a wellestablished concept and has been a central focus in discussions on doctor-patient relationship and medical institutions (Foucault, 1973; Foucault, 1965; Driver, 1994; Charon et al., 1994; Mishler, 1994; Scambler, 2001; Di Blasi et al., 2001; Willems, 2005; Epstein et al., 2005). The communication behavior of doctors is influenced by various factors such as the patients' sociodemographics, language, income, education, class, race, and gender (Perez-Stable, 1997; Katz, 2007; Taira et al., 1997; Pendleton \& Bochner, 1980; Street, 1991; Street \& Buller, 1988).

Health inequality and inequity studies in India focus mostly on factors such as availability, accessibility and affordability of health care across regions, hospitals and social and economic groups, using often quantitative methods (Bhan et al., 2016; Deaton and Dreze 2009; Subramanian et al., 2006; Mohanty \& Pathak, 2009; Sen et al., 2002; Sen and Iyer, 2012; Iyer et al., 2007; Malhotra \& Do, 2012). Few studies suggest that health inequities take place at the intersection of gender, class, caste, and regional differences (Baru et al., 2010; Jungari \& Chauhan, 2017; Iyer et al., 2007; Padma et al., 2010; Das and Hammer, 2007). Very few qualitative studies discuss the interpersonal relationship and its influence on doctor-patient relationship and focus on provision of care from the provider's and receivers perspective (Whitehead et al., 2001; Balarajan, et al., 2011; Mocherla et al., 2011; Fochsen et al., 2006). Most of the studies offer a macro-perspective of health 
inequality and inequity issues, often overlooking or understating the significance of microinequities. Micro-inequities are not blatant forms of discrimination: they are minute expressions and events, which can or cannot be recognized by victims and perpetrators (Rowe, 1990). These are acts which one cannot pin point or fight over, and one cannot sue the perpetrator of such subtle forms of discrimination. These are unfair and unjust actions inflicted on the individuals who are marginalized on the basis of gender, caste, class, age, economic group, etc. Recently this concept of microinequities was employed to understand the pervasive negative attitude doctors express towards obese patients across different clinical situations (Shwartz et al., 2003; Sabin et al., 2012 ).

This paper aims to capture micro-inequities through qualitative analysis, highlighting the need to emphasize the moral significance of micro-inequities in the doctor/nurse-family/patient relationship, and in the health care system. Micro-inequities is one of the key concept with which I engaged in my doctoral dissertation on the concept of consent in elective medical intervention and medical judiciary in the Indian context. In this paper, I investigate micro-level events, expressions and interactions of surgeons, nurses, patients' and patients' family members through in-depth interviews and observation data. The purpose of this paper, however, is not to ascertain the presence of social inequalities, but to explicate how micro-inequities influence relationships within hospital settings by mirroring and extending the inequalities in the society and how micro-inequities diminish the dignity of patients/family members and result in poorer communication and an eventual normalization of these experiences by the agents (both victims and perpetrators). My analysis illustrates how normalization and legitimization of micro-inequities build on the existing asymmetrical power relationships. 


\section{Methodology, methods and reflexivity}

I employed constructivist-interpretative paradigm, supplemented by critical theory, to analyze the power equations within relationships of individuals and institutions involved and structural factors across different clinical establishments/institutions. Constructivist grounded theory method was adopted to create conceptual frameworks through inductive analysis (Strauss and Corbin, 1990 Charmaz, 2008; Charmaz, 2017). Through the deployment of interpretative and inductive methods during data collection and analysis, the experiences and voices of those who experience micro-level discriminatory events and experiences are captured. This approach helps us to enrich the understanding of micro-inequities, by taking into account the perspective of the individuals and lived experienced of micro-inequities. Observation and in-depth interviews were conducted after obtaining permission from both hospital ethics committees and consent of participants. In-depth interviews were conducted in the three wards-General Surgery, Obstetrics \& Gynecology (O\&G), and Orthopedics-of one government hospital (GH) and one private hospital (PH) in Chennai, from December 2016 to July 2017. Interviews with surgeons were based on the snowball principle, and thus interviews were conducted with the help of surgeons from other hospitals in Chennai. These interviews were conducted during the period of February 2016 to July 2017. With its multi-and super-specialty hospitals-both in private and public sector- Chennai attracts patients from diverse parts of the country and the other countries.

Observation was conducted within both hospital premises using the complete observer stance (Kawulich, 2005). I was in plain sight in hospital settings: in wards, corridors, lawns, waiting rooms and canteens. To better understand and examine the concept studied, I conducted thirty six in-depth interviews with patients and family members, sixteen interviews with surgeons and eleven interviews with nurses. Overall, sixteen patients and eight family members of patients at GH and twelve PH patient units (including patients' family members) were interviewed. In government 
hospitals, family members were allowed in the ward only during specified visiting periods or in exceptional situations when the patient requires continuous attention. The rationale behind this restriction is the space constraint in the wards where each room/ward is filled with beds spaced at an arm's length. As a result of this, only three GH patients were accompanied by family members during the interview, and the remaining interviews with the family members of patients in GH were conducted outside the ward. At the same time, each patient in the private hospital was accompanied by his/her family member/s in their private room. Hence, all the interviews in the private hospital were in-depth group interviews. Table 1 to 4 gives an overview of the profile of the participants.

Interviews with the patients at GH were conducted based on the information provided by ward nurses about post-surgery recovery patients. Most of the interviews with family members were conducted in common areas common areas like corridors and waiting rooms. At the private hospital, I Interviewed patients and their family members based on the information provided by junior doctors (Post Graduate) in charge of the ward. The interviews were conducted based on a semistructured questionnaire based on expert opinion. The duration of interviews ranged from twenty five minutes to two hours. I interacted with the participants in the GH in Tamil language whereas both English and Tamil language were used for my interaction with the participants at the PH. Except government hospital interviews (Permission for audio-recording was denied by GH Director), all interviews were audio-taped. Interviews of GH participants were recorded using short hand and major notes was immediately noted. Interviews recorded was translated and transcribed. The data collected was analysed using grounded theory method (Strauss and Corbin, 1990, Charmaz, 2008). Initially I employed open coding after which code categories were prompted. Later constructed themes were analysed. This interpretation process was guided by literature on asymmetrical doctor-patient relationship and how power operates in different institutions (Foucault, 1965; Fleming and Spicer, 2007). Drawing on studies (Rowe, 1990; Dovidio and Hebl, 2005) and 
my understanding of what constitutes an unfair treatment, I identified certain events, expressions and experiences as “micro-inequities”. I employed reflexive analysis to critically question and understand the concept through data and existing studies. I have reflectively analyzed my position as a cis-female from a lower middle class social location with a privileged educational background. I was raised in a Hindu lower middle class, intermediate caste family in a semi-urban area. The personal experiences of both blatant and subtle forms of class, caste and gender discriminations in family settings, social gatherings, and academic spaces have shaped my doctoral research as well as this paper on “micro-inequities”.

\section{Findings: Identifying and Conceptualizing Micro-inequities}

Inequalities exist in our society in different variants and contexts, and are experienced in varying degrees by different individuals and communities. During my research to understand how consent is understood within the sphere of clinical treatment, I observed that the nature of communication between different individuals varies within different medical institutions and that the variation is subtle. There is an established body of scholarly literature on understanding power, medical knowledge and clinical encounter (Elston, 1991; Lupton, 1997; Foucault, 1977; Lindenbaum \& Lock, 1993). Rowe (1990) treats micro-inequities as “apparently small events, which are often ephemeral and hard to prove; events that are covert, often unintentional, frequently unrecognized by the perpetrator." This understanding of micro-inequities, applied in the context of medical institution, provides us with another lens for looking at the power relationships, and its process and influence on individuals being affected. The findings of my analysis strongly suggest that microinequities are experienced by patients and family members of diverse backgrounds, and the degree of variation is strongly linked to their socio-economic status, education level, age, gender and the nature of the hospital of stay. To illustrate and understand the concept better I have treated micro- 
inequities as an interplay or overlap of two experiences: interpersonal discrimination and micromessaging.

\section{Discrimination Woven into the Everyday: Micro-inequities in a Government Hospital}

In government hospitals, the micro-inequities primarily consist of interpersonal discrimination (Concept referred in McConahay, 1986; Hebl et al., 2002). Interpersonal discrimination here refers to events and expressions such as doctors frequently avoiding interaction with aged patients/family members, eye-rolling while talking to educated female patients/family members, not paying enough attention during consultation or while under treatment, ‘a loud exhausting sigh' by care providers during consultation, etc. Even though scolding/yelling is a manifest act, it is perceived as a subtle act or expression in GH because it is perceived as necessary for managing the "crowd" in an overburdened hospital setting. A senior female nurse, for instance, claimed: “see these people don't comply if we talk nicely. We should manage them to give care”. For patients and their family members these acts are a part of their experience of the GH. Though it is an explicitly manifested form of inequality, it is normalized by the victims as a necessary part of care-giving while the perpetrators too deem it to be necessary for care-giving. These experiences are all too familiar for the patients who are often subjected to similar subtle acts outside the hospital setting too. Vani (I have used fictional names), a young woman, the caretaker of her mother who was recuperating in the O\&G ward after surgery, felt that there was a deliberate lack of attention from the nurses, and was dejected with being treated with disrespect.

I keep following them [the doctors], from ward to their offices and back. they don't even bother to stop for a second and listen to me. I don't know what is wrong with my mother. We have been here for the past 15 days. Some days back, the junior nurses told me that it is some infection. They performed a surgery again, but did not tell me anything about it: why or what. As everywhere else, we are made to keep waiting.

Vani, 22, Garment factory worker 
While sharing her experience of feeling anxious about her mother's health, Vani said she felt she was invisible to the doctors and nurses. The fatalistic tone in her voice suggests that discrimination constitutes a routine experience for her at a government hospital. The feeling of being ignored and the need to keep pleasing people in power can be observed in her account. Statements such as "I keep following them, from ward to their offices and back”, and “they don't even bother to stop for a second and listen to me”, are manifestations of instances of micro-inequities Vani faced. Being scolded, yelled at, stared at, and questions/queries not being acknowledged are some of the recurring issues that patients and their family members face in government hospitals. Let us look at, for instance, the account of Mary, mother of a 26 year old male mechanic who had met with an accident and got admitted for knee surgery.

There is no one to take care of us. He was admitted five days ago. I cannot stay inside the ward for more than the briefest of periods. The senior staff nurse scolds me, if she sees me when I visit him. I walk out immediately when she stares at me. It is my fate that I can't take him to a private hospital. Well, this is how we are treated everywhere.

Mary, 41, fish vendor

The statement, "I walk out immediately when she stares at me” demonstrates how "staring” or any eye contact becomes an expression of authority. Throughout interviews at GH, I observed two positions recurring. On the one hand, patients were content with "whatever" they were getting as they were receiving treatment free of cost. On the other hand they expressed displeasure over being treated without respect and helplessness over not having a choice. Let us look at the experience of Kumar, who underwent surgery for hernia surgery at a government hospital:

The operation and all went well. We are happy here. We heard that this is the best among the government hospitals. Where else can people like us go? We don't have money, so we get what we always get.

Kumar, 38, Sanitation worker

Most of the patients at the government hospital felt that their experience of pain was often discounted and discarded. Meenu, a patient, 37 years, female, who does household job, for instance, said: “...here they send us back by making us remember the pain, but maybe in big private hospitals, pain is not at all felt...”. This experience of interpersonal discriminations can be understood as being 
a part of micro-messaging. Micro-messaging is an experience or event where some people are valued and respected by others whereas others are disregarded, devalued and disrespected (Young, 2006). Patients and family members in the GH refer to themselves as people who are not seen as respectable and feel disregarded, in comparison with patients at $\mathrm{PH}$. GH patients and their family members often express their perception of how $\mathrm{PH}$ patients are in a better position and that they ought to be respected as they are paying for treatment as well as for courteous service. As GH patients don't pay for the service and are treated "free of cost", they feel that they are "treated" the way they are because of their "fate” and feel "helpless" with "no choice”.

Tamil shares her experience in the government hospital. She was a bystander for her sister who had undergone Dilatation and Curettage (D \& C) surgery and was undergoing post-surgery treatment for heavy bleeding. Tamil was a working woman and her brother was in school. She had to take leave from work to take care of her sister.

Something happened to my sister. It [the treatment] is taking more time. I don't know what to do; I have to go to work. It's been 15 days. I have been trying to meet the doctors for the past few days, as nurses are not telling me anything properly. I understand that doctors are busy and have no time for us. But I am worried. If they tell me clearly I will know better what to do.

Tamil, 27, Housekeeping worker at a small company

Though patients and their family members of the GH are upset with the treatment meted out to them, they justify their position within the larger context, and normalize the situations, experiences and interactions. Doctors and nurses in GH rationalize their paternalistic attitude towards patients and their family members as necessary to maintain order in the overburdened system. Analysis of data suggested that though patients and family members of patients feel unfairly treated, they empathize with doctors and nurses who are seen as over-stressed and overburdened. 
Analysis of the accounts of doctors and nurses from both PH and GH demonstrates that doctors and nurses perceive patients and family members of patients in general as "ignorant". This is particularly the case in GH where most doctors expressed the feeling that the patients who go to GH are "poor” and "illiterate” and “cannot understand”. They see their role as that of "playing God” and state that it is important for them to "act like a God" to ensure that patients trust them and "do what is best for them". Taking up the role of the powerful benefactor or benign "God" allows the doctors to occupy and sustain their position of power. These imbibed perceptions of doctors make them expect the patients to fit into the role of what they consider as the ideal patient who ought to blindly accept, trust and not question the doctor. Similar expectations and ideas of the ideal patient were reported in Fochsen et al (2006). One of the surgeons felt:

...He also trusts me because his neighboring patient is getting well and [all] right etc... He spends long hours in theater and [I] am trying to help him a lot. That's all. [If] there is [a] literate patient, he has a lot of options to go [to] some other hospitals, so I must give more options. Whereas this person has no option and [has] come to me think[ing] of me as a God. I act like a God. I'll try to do the best possible. I may not explain to him but I will...

\section{Dr. Krishna, 58, Vascular Surgeon, GH}

Nurses in GH see themselves as the ones managing the day-to-day operations of the whole organization. They see themselves as engaged in both care-giving as well as administrative activities, which results in them being hard pressed for time. Nurses too are in positions of authority and are seen as such by patients and their family members. They take up the role of policing the wards and act as strict disciplinarians. Meenakshi, a 42 year old senior nurse in the O\&G ward said: "Madam, we need to shout at them, otherwise they will not listen. We will take care of them, that's our job. We make sure they get well soon”. From interviews with doctors and nurses in the GH, it emerges that patients and their family members are perceived as individuals "who cannot understand”, “cannot make decisions” and need to be "disciplined”. Patients and their family members are constantly controlled through blatant or subtle actions. 


\section{In private hospital: Manifestations of Micro-inequities}

Micro-inequities play out differently in private hospitals. Though there are differences between micro-inequities in a private hospital and a government hospital, there are a common set of factors that influence behavior: socio-economic status, linguistic identity, education level, personal presentation, and so on. Compared to the situation in government hospitals, doctors/surgeons, nurses and other hospital staff are more respectful towards patients and their family members. An easily observable manifestation of this is the use of polite language and polite manner of speaking to patients and their family members. During my field work at the private hospital, I did not come across nurses shouting or yelling at patients or their family members. The nurses and doctors always wore a smile and were very cordial with the patients and their family members. However, there were some instances which bordered on interpersonal discrimination. For instance there were certain occasions when a) a senior male surgeon was checking his mobile phone while talking to an old male bystander (wearing dhoti and perhaps hailing from a rural area), b) a senior female staff manager interrupted and did not listen to a middle-aged female bystander (wearing sari, heavy and old-fashioned gold chains and possibly hailing from a rural area) c) a male Post Graduate doctor simply nodding without paying much attention and heaving a deep sigh while listening to a female caretaker who was asking questions in English (may have been well educated and from a higher class).

The observation and interpretation of micro-events or experiences mentioned are transient, subtle and tiny. Compared to GH participants, there were significant differences in the demographics of the participants at the $\mathrm{PH}$ and their experiences and perception of micro-inequities. Though there were certain instances of micro-inequities in $\mathrm{PH}$, especially based on gender, class and geographic divide (the rural-urban divide and stereotypes), the degree was milder. One could perceive in the patients and their family members in the $\mathrm{PH}$ a noticeably higher level of confidence and lack of 
hesitation in exercising their right to get the service they felt they deserved. For example, Mani, a patient, mentioned that the doctors were very kind and that he could ask questions about whatever he wanted to know.

Sure, I should know what is happening. How long will I be like this? In general I have to know. He was kind to tell, because it is totally new. Colonoscopy. It is a new technical term for me. I asked him all my doubts. I asked my son also to know about the treatment. My son discussed everything with the doctor and told me not to worry.

Mani, Male, 51, Bank Manager

Patients and family members demand "professionalism" from the part of the caregivers and feel that they deserve respectful treatment from the caregivers as part of the service they pay for. During the interviews, most of them recounted their earlier experiences in other private hospitals. From my interaction with the patients it emerged that patient satisfaction is strongly linked to the way they are treated, acknowledged and respected by the care providers. The patients are aware of their rights as consumers or clients in a service industry like healthcare. They were aware of their own position as consumers or clients in a service industry. All the patients and their family members had taken pains to make inquiries about the hospital before deciding to get treated there. Mangai, who was taking care of a patient who had undergone surgery on the knee cap, shared her reflections:

Here the staff are very nice and helpful. They make sure that the patient is comfortable. Based on our friends' opinion and our family doctors' second opinion we came here. The quality of service is good. My brother has talked to the doctor, and discussed everything. They are professional, unlike other private hospitals. Our last experience was very bad though it was at a big branded hospital, hospital " $\mathrm{X}$ ". They did not bother to talk properly. As of now, here it is not like that. We pay to get good quality service.

Mangai, 31, Software engineer

Like many patients and family members in this hospital, Mangai expected and demanded respect from care providers and felt that it was owed to them as they were paying for the service. Though we could find patients and caretakers performing their roles as consumers demanding appropriate service as their right, many of them felt that they could not question the doctors as much as they wanted as they are afraid that they may "annoy” the doctors by being too "demanding”. They 
perceive doctors as an "authoritative" figures and try not to "annoy or irritate" them to maintain a warm relationship. While there has always been an asymmetry in the power relationship, microinequities can be observed at various levels of care providing. For example, Saraswathi, a 51 year old house wife and the spouse of a patient who was sitting in the corridor and was about to be discharged from the hospital said, in a matter of fact tone:

This place is nice. I don't know much about the treatment; it is a surgery. I asked the nurse what food to give and what medicine to take. She did not discuss anything with me. She just walked away and said she will inform my son.

Not paying attention and walking away when asked a question shows the subtle manner in which the nurse disregarded Saraswathi. The nurse felt that the mother was not a significant enough person and that the son was the actual decision-maker in the family. Though it is generally perceived that “women” are seen as “caretakers” and are provided information on post-operative care, the incident here gives us another perspective. Even though this shows how the gender of the patient/family member influences the way they are treated, this anecdote also reveals an instance of mico-inequity. The caretaker expressing her displeasure about the nurse "walking away" gives us a hint of how micro-inequity operates in this context. The gender and the status of the patient/family member within the structure of the family influence how they are treated by the caregivers in the hospital. In the case of most families, including that of Saraswathi's, the young male earning member plays the dominant role of decision-maker and is seen and recognised as such by the hospital staff. The same tendency can be observed in the context of GH too. It is evident that doctors and nurses embrace the cultural norms of the society and their behaviour towards patients and their family members is heavily influenced by the social norms they have imbibed.

It emerges from interviews with $\mathrm{PH}$ doctors and nurses that they view patients and family members as consumers who should be provided with good "quality of care" and that patients expect 
“professionalism” from their care providers. It also emerged that "patient rights' within the legal framework is respected with respect to disclosure of information and medical decision-making. Most surgeons deem it important to provide the patients with adequate information before obtaining patients' signature in the consent forms, as it can be used as evidence if any lawsuit is initiated against them. Dr. Sriram, 55 year old senior male general surgeon said, for instance:

...things have changed. Here we are professionals who should treat patients as people with rights as consumers. They can sue us if we don't maintain proper records. They come for our time and quality of service, and thus they are entitled to their rights. We treat them well. That is the way it works...

During the interviews with the nurses, they repeatedly stressed on the importance of maintaining cordial relations with patients and their family members as the "hospital protocol”, which stresses on providing “quality care”, demands such a cordial relationship. A senior female staff nurse, Ms. Lakshmi, 41 years old said: “we try our best to provide quality care. We are an accredited hospital and strictly follow the protocols". The patients and their family members generally had a positive perception on the quality of care at this particular private hospital. In the private hospital, patients/family members are consumers or clients who pay for the service and thus demand quality service. An observation of "provider-client relationship" reveals that, on the one hand, patients/family members view themselves as consumers or clients seeking and demanding good quality of service. Care providers, on the other hand, view themselves as professional service providers who render services and respect the rights of the patients as per the protocols. They also maintain documents to protect themselves from potential lawsuits. The doctor-patient interactions are influenced by particularities such as the history of the medical institution, management, training and practice of individuals. From the discussion in this section, it emerges that there are certain commonalities when it comes to micro-inequities that reflect the larger inequities, though the degree of these experiences may vary. 


\section{Discussion}

From the observation data and the accounts of participants across different medical institutions, the themes constructs that subtle, micro-events and experiences occur at the medical institutions at varying degrees. In the following section I discuss how these micro-equities are normalized through the process of producing and maintaining the unequal power relations in the doctor-patient relationship in the hospital setting. I argue that there is a need to identify and reiterate the moral significance of micro-inequities while discussing larger inequalities within medical institutions and the doctor-patient relationship.

\section{Normalization of Micro-inequities}

Academic studies on workplace discrimination and minority studies suggest that it is difficult to grasp micro-inequities or subtle discriminating events and experiences (Cortina, 2008; Rowe, 1990). In this paper, my attempt has been to further the understanding of micro-inequities in hospital settings where experiences of micro-inequities are normalized, with agents play out the social roles expected of them and accept certain institutional mechanisms as necessary and inevitable. Micro-inequities that patients and their family members experience in government hospitals are legitimized, with the patients accepting or even expecting the care providers to be "authoritative". Further, their experiences are normalized as they fatalistically see themselves as individuals devoid of any choice. At the same time, in the $\mathrm{PH}$ the patients are aware of their rights as consumers and expect to be treated with respect, despite seeing care providers as "authoritative”.

There are many sources of power to control and dominate certain group of individuals (Sidanius, \& Pratto, 1999). In the context of medical institution, which is the intersection of hospital, society, and individuals, ideas such as “professionalism”, “intelligence”, and "knowledge” play significant roles. Along with various sources of power, socialization and indoctrination processes of the society 
contribute to the sustenance and reproduction of unequal power relationships (Noel, 1994, Hurst et al., 2007). The data shows how "hospital settings" can sustain and reproduce unequal power relations through practices of “micro-inequities”. Subtle experiences of power imbalances are part of the everyday experiences of most people, but individuals from certain social strata normalize and neutralize their experiences within the GH to a much greater extent because of the larger inequalities and structural factors around them.

The most significant effect of these micro-level experiences is that it affects the dignity of the patients and their family members. Furthermore, they affect communication process, as patients and family members are intimidated by the exercise of power. This intimidation results in patients and their family members hesitating to approach doctors, nurses and other staff, even when there is a necessity to discuss clinical treatment options, post-operative treatment plan and associated risks. Thus, subtle discrimination further pushes patients in the GH into being oppressed by the preexisting social hierarchy that generates the unequal caregiver-patient/family member relationship. While there are extensive discussions within academic and public spheres that suggest moving away from paternalism to a more equal doctor-patient relationship through the creation of mechanisms to protect patients' rights and dignity, the micro-inequities act as barriers to the realization of a more equal relationship. The analysis above suggests that the patients and family members in both the $\mathrm{GH}$ and the $\mathrm{PH}$ are aware of the micro-inequities and pre-existing power hierarchies, and have normalized and legitimized their experiences, albeit in a slightly bitter and fatalistic manner.

\section{Micro-inequities practiced within larger inequalities}

In a macro-level process of power, ingrained in a macro-context, micro-inequities are influenced by existing power discourses of the society. Any action or experience is influenced by its social 
context, as it determines who is exposed to what kind of experience, on the basis of what, and where they experience it. This study observed how micro-inequities within both the hospital settings establish their processes; cause certain effects and how they influence the medical institutional climate and relationships in varying degrees. Traditional hierarchical structures are ingrained within the field of medicine and medical institutions, which sustain the asymmetric relationships (Valentine, 2014; Halford \& Leonard, 2003). There is already a large body of literature establish that medical system is based on a patriarchal ideology, where the knowledge of medical professionals is deemed superior and the patient is viewed as ignorant (Leventhal et al. 2005). This patriarchal and hierarchical system is often viewed as a system which maintains order to realize the idealized notions of institutional roles (Hurst et al., 2007). Drawing on Foucault’s (1977) understanding of power relations, it may be argued that the very "resistance and being aware” of the subtle discriminations by patients and their family members illustrates the existence of power exercised by care-providers and the institutions.

There have been a very few qualitative studies that have explored the interpersonal relationships within different hospitals in the Indian context (Rani et al., 2007; Padma et al., 2010; Whitehead et al., 2001; Balarajan et al., 2011). Studies suggest that micro-inequities arise because of lower tolerance to more blatant forms of discrimination in societies with rule of law and strong societal values (Cortina, 2008). Through a discussion of my findings, I argue that subtle discrimination is a reflection of existing forms, and they are as harmful as blatant actions. Different kind of subtle experiences are experienced differently in different medical institutions. The findings of the study suggest that GH patients and their family members are treated the way they are because they are poor and illiterate, who cannot "understand" and thus need to be "disciplined" by figure of authority. This exercise of authority takes place at all levels in varying degrees. While some nurse/doctors “dismiss" and "infantilize” the views of patients and their family members, some 
others perform exercise power by being rude, by scolding or yelling at the patients and their family members. At the same time, in $\mathrm{PH}$, patients and their family members are treated as "consumers" with "patients' rights" and care providers act "professionally" according to the protocols of the hospital to maintain "the standard of care" and to insulate themselves against any potential lawsuits. It may be pointed out here that the distinction made between $\mathrm{GH}$ and $\mathrm{PH}$ experiences should not be taken as absolute. The experiences of individuals suggest that micro-inequities experienced in medical institutions are part of the larger inequalities in the society which are based on class (caste within Indian context), age, gender and geographical factors.

\section{Moral significance of Micro-Inequities}

Health research studies in India focus on larger inequalities and inequity issues of the society (Baru et al., 2010; Jungari \& Chauhan, 2017; Iyer et al., 2007). These studies often overlook micro-level experiences. The findings of my study establish the presence of micro-inequities and illustrates their processes and influences within hospital settings. Even moral theories often overlook the presence of micro-inequities because of their characteristics of being small, subtle events and experiences. (Parfit, 1984). The philosopher Kernohan (1998) discusses micro-inequities under moral theories, using the Cumulative Effect Principle. However, this principle gives significance only to the overall harmful effects. While it is necessary to take into account the overall effect, specific subtle or micro-level harm or event should be given moral significance by considering the context or situation. Micro-inequities are ephemeral, small harms which diminish the dignity of patients and their family members. These micro-inequities are normalized and legitimized within the hierarchical order in the hospital setting. Thus, micro-inequities lead to the maintenance, sustenance, and reproduction of the asymmetrical power relationship. It is important to pay attention to micro-inequities while discussing the larger inequality and inequity issues within the medical field. However, micro-inequities are either treated as part of larger issues at hand and thus 
overlooked or unacknowledged. Owing to their transient and subtle nature, it is difficult to eliminate micro-inequities by setting up protocols or through stringent laws. For instance, if a doctor heaves a sigh of exasperation, wears an inattentive expression while attending to a patient, one cannot complain against the doctor. That is where looking beyond the legal framework becomes important. Thus, it is important to address the moral significance of micro-inequities within the medical field. This requires self-reflexive introspection from the part of individuals involved in health care system and institutions.

\section{Conclusion}

This paper illustrated the central role micro-inequities play in sustaining and reproducing asymmetrical power relationships in the hospital settings. Subtle, micro events and experiences play a significant role in marinating the power relations between individuals and create an institutional climate hostile towards patients and their family members. Through an analysis of the data, I showed how the degree of subtle experiences and their effects vary in different settings such as the private hospital and the government hospital. Micro-level discriminations or experiences are a reflection of the power equation-who belongs to the system and who does not. The power of transient and micro-level harms lies in their ability to be normalized and legitimized through "knowledge" and "professional roles" in the institutions. It is difficult to arrive at the ethical practice of medicine with dignity and respect to all individual irrespective of their different socioeconomic and inter-sectional backgrounds if micro-inequities are not given moral significance while discussing the barriers in doctor/nurse-patient/family relationship and institutional climate in hospital settings. 


\section{References}

Balarajan, Y., Selvaraj, S., \& Subramanian, S. V. (2011). Health care and equity in India. The Lancet, 377(9764), 505-515.

Baru, R., Acharya, A., Acharya, S., Kumar, A. S., \& Nagaraj, K. (2010). Inequities in access to health services in India: caste, class and region. Economic and Political Weekly, 49-58.

Bhan, N., Rao, K. D., \& Kachwaha, S. (2016). Health inequalities research in India: a review of trends and themes in the literature since the 1990s. International journal for equity in health, 15(1), 166.

Bensing, J. (1991). Doctor-patient communication and the quality of care. Social science \& medicine, 32(11), 1301-1310.

Branscombe, N. R., Schmitt, M. T., \& Harvey, R. D. (1999). Perceiving pervasive discrimination among African Americans: Implications for group identification and well-being. Journal of personality and social psychology, 77(1), 135.

Charon, R., Greene, M. G., \& Adelman, R. D. (1994). Multi-dimensional interaction analysis: a collaborative approach to the study of medical discourse. Social science \& medicine, 39(7), 955965.

Charmaz, K. (2008). Constructionism and the grounded theory method. Handbook of constructionist research, 1, 397-412.

Charmaz, K. (2017). The power of constructivist grounded theory for critical inquiry. Qualitative inquiry, 23(1), 34-45.

Cordella, M. (2004). The dynamic consultation: a discourse analytical study of doctor patient communication (Vol. 128). John Benjamins Publishing.

Corbin, J., \& Strauss, A. (1990). Grounded theory research: Procedures, canons and evaluative criteria. Zeitschrift für Soziologie, 19(6), 418-427. 
Cortina, L. M. (2008). Unseen injustice: Incivility as modern discrimination in organizations. Academy of management review, 33(1), 55-75.

Dovidio, J. F., \& Hebl, M. R. (2005). Discrimination at the level of the individual: Cognitive and affective factors. Discrimination at work: The psychological and organizational bases, 11-35.

Das, J., \& Hammer, J. (2012). Health and Health Care Policy in India: The Case for Quality of Care. The Oxford Handbook of the Indian Economy, 420.

Deaton, A., \& Dreze, J. (2002). Poverty and inequality in India: a re-examination. Economic and political weekly, 3729-3748.

Driver, F. (1994). Bodies in space: Foucault's account of disciplinary power. Reassessing Foucault: Power, medicine and the body, 113-131.

Duffy, F. D., Gordon, G. H., Whelan, G., Cole-Kelly, K., \& Frankel, R. (2004). Assessing competence in communication and interpersonal skills: the Kalamazoo II report. Academic Medicine, 79(6), 495-507.

Di Blasi, Z., Harkness, E., Ernst, E., Georgiou, A., \& Kleijnen, J. (2001). Influence of context effects on health outcomes: a systematic review. The Lancet, 357(9258), 757-762.

Elston, M. A. (1991). The politics of professional power: medicine in a changing health service. The sociology of the health service, 58-88.

Epstein, R. M., Franks, P., Fiscella, K., Shields, C. G., Meldrum, S. C., Kravitz, R. L., \& Duberstein, P. R. (2005). Measuring patient-centered communication in patient-physician consultations: theoretical and practical issues. Social science \& medicine, 61(7), 1516-1528.

Epstein, R. M. (2013). Whole mind and shared mind in clinical decision-making. Patient Education and Counseling, 90(2), 200-206.

Essers, G., Kramer, A., Andriesse, B., van Weel, C., van der Vleuten, C., \& van Dulmen, S. (2013). Context factors in general practitioner-patient encounters and their impact on assessing communication skills-an exploratory study. BMC family practice, 14(1), 65. 
Fleming, P., \& Spicer, A. (2007). Contesting the corporation: Struggle, power and resistance in organizations. Cambridge University Press.

Foucault, M. (1965). Madness and Civilization, trans. Richard Howard. New York, Pantheon.

Foucault, M. (1973). The Birth of the Clinic, trans. A. Sheridan, London: Tavistock.

Foucault, M. (1977). Discipline and Punish, trans. Alan Sheridan (New York: Vintage, 1979), 242.

Fochsen, G., Deshpande, K., \& Thorson, A. (2006). Power imbalance and consumerism in the doctor-patient relationship: health care providers' experiences of patient encounters in a rural district in India. Qualitative health research, 16(9), 1236-1251.

Griffin, S. J., Kinmonth, A. L., Veltman, M. W., Gillard, S., Grant, J., \& Stewart, M. (2004). Effect on health-related outcomes of interventions to alter the interaction between patients and practitioners: a systematic review of trials. The Annals of Family Medicine, 2(6), 595-608.

Halford, S., \& Leonard, P. (2003). Space and place in the construction and performance of gendered nursing identities. Journal of Advanced Nursing, 42(2), 201-208.

Hebl, M. R., Foster, J. B., Mannix, L. M., \& Dovidio, J. F. (2002). Formal and interpersonal discrimination: A field study of bias toward homosexual applicants. Personality and Social Psychology Bulletin, 28(6), 815-825.

Hurst, C. E., Gibbon, H. M. F., \& Nurse, A. M. (2007). Social inequality: Forms, causes, and consequences. Routledge.

Iyer, A., Sen, G., \& George, A. (2007). The dynamics of gender and class in access to health care: Evidence from rural Karnataka, India. International Journal of Health Services, 37(3), 537-554.

Jungari, S., \& Chauhan, B. G. (2017). Caste, Wealth and Regional Inequalities in Health Status of Women and Children in India. Contemporary Voice of Dalit, 9(1), 87-100.

Katz, J. D. (2007). Conflict and its resolution in the operating room. Journal of clinical anesthesia, 19(2), 152-158.

Kernohan, A. (1998). Liberalism, equality, and cultural oppression. Cambridge University Press. 
Kawulich, B. B. (2005, May). Participant observation as a data collection method. In Forum Qualitative Sozialforschung/Forum: Qualitative Social Research (Vol. 6, No. 2).

Leventhal, M. J., Riegel, B., Carlson, B., \& De Geest, S. (2005). Negotiating compliance in heart failure: remaining issues and questions. European Journal of Cardiovascular Nursing, 4(4), 298307.

Lupton, D. (1997). Consumerism, reflexivity and the medical encounter. Social science \& medicine, 45(3), 373-381.

Lindenbaum, S., \& Lock, M. M. (Eds.). (1993). Knowledge, power, and practice: the anthropology of medicine and everyday life (No. 36). Univ of California Press.

Malhotra, C., \& Do, Y. K. (2012). Socio-economic disparities in health system responsiveness in India. Health policy and planning, 28(2), 197-205.

Marvasti, A. (2003). Qualitative research in sociology. Sage.

McConahay, J.B. (1986). Modern racism, ambivalence, and the modern racism scale. In J. F. Dovidio \& S. L. Gaertner (Eds.), Prejudice, discrimination ,and racism (pp. 91-125). Orlando, FL: Academic Press.

Mishler, E. G. (1984). The discourse of medicine: Dialectics of medical interviews (Vol. 3). Greenwood Publishing Group.

Mohanty, S. K., \& Pathak, P. K. (2009). Rich-poor gap in utilization of reproductive and child health services in India, 1992-2005. Journal of biosocial science, 41(3), 381-398.

Mocherla, S., Raman, U., \& Holden, B. (2011). Clinician-patient communication in a glaucoma clinic in India. Qualitative health research, 21(3), 429-440.

Noël, L. (1994). Intolerance: A general survey. McGill-Queen's Press-MQUP.

Padma, P., Rajendran, C., \& Sai Lokachari, P. (2010). Service quality and its impact on customer satisfaction in Indian hospitals: Perspectives of patients and their attendants. Benchmarking: An International Journal, 17(6), 807-841. 
Parfit, D. (1984). Reasons and persons. OUP Oxford.

Pendleton, D. A., \& Bochner, S. (1980). The communication of medical information in general practice consultations as a function of patients' social class. Social Science \& Medicine. Part A: Medical Psychology \& Medical Sociology, 14(6), 669-673.

Pérez-Stable, E. J., Napoles-Springer, A., \& Miramontes, J. M. (1997). The effects of ethnicity and language on medical outcomes of patients with hypertension or diabetes. Medical care, 35(12), 1212-1219.

Ramsden, E. L. (1975). The patient's right to know. Implications for interpersonal communication processes. Physical therapy, 55(2), 133-138.

Rani, M., Bonu, S., \& Harvey, S. (2007). Differentials in the quality of antenatal care in India. International journal for quality in health care, 20(1), 62-71.

Rowe MP. (1990). Barriers to equality: The power of subtle discrimination to maintain unequal opportunity. Employee Responsibilities and Rights Journal 3(2): 153-163.

Sabin, J. A., Marini, M., \& Nosek, B. A. (2012). Implicit and explicit anti-fat bias among a large sample of medical doctors by BMI, race/ethnicity and gender. PloS one, 7(11), e48448.

Street, R. L., \& Buller, D. B. (1988). Patients’ characteristics affecting physician-patient nonverbal communication. Human Communication Research, 15(1), 60-90.

Street, R. L. (1991). Information-giving in medical consultations: the influence of patients' communicative styles and personal characteristics. Social science \& medicine, 32(5), 541-548.

Scambler, G., \& Britten, N. (2001). System, lifeworld and doctor-patient interactions. Habermas, Critical Theory and Health. Scambler G. London: Taylor and Francis.

Schwartz, M. B., Chambliss, H. O. N., Brownell, K. D., Blair, S. N., \& Billington, C. (2003). Weight bias among health professionals specializing in obesity. Obesity, 11(9), 1033-1039.

Stewart, M., Brown, J. B., Boon, H., Galajda, J., Meredith, L., \& Sangster, M. (1999). Evidence on patient-doctor communication. Cancer, 25(1999), 30. 
Subramanian, S. V., Nandy, S., Irving, M., Gordon, D., Lambert, H., \& Davey Smith, G. (2006). The mortality divide in India: the differential contributions of gender, caste, and standard of living across the life course. American Journal of Public Health, 96(5), 818-825.

Sen, G., Iyer, A., \& George, A. (2002). Structural reforms and health equity: a comparison of NSS surveys, 1986-87 and 1995-96. Economic and Political Weekly, 1342-1352.

Sen, G., \& Iyer, A. (2012). Who gains, who loses and how: leveraging gender and class intersections to secure health entitlements. Social science \& medicine, 74(11), 1802-1811.

Sidanius, J., \& Pratto, F. (2001). Social dominance: An intergroup theory of social hierarchy and oppression. Cambridge University Press.

Schuster, M. A., Collins, R., Cunningham, W. E., Morton, S. C., Zierler, S., Wong, M., \& Kanouse, D. E. (2005). Perceived discrimination in clinical care in a nationally representative sample of HIVinfected adults receiving health care. Journal of general internal medicine, 20(9), 807-813.

Stewart, M. E., \& Roter, D. E. (1989). Communicating with medical patients. Sage Publications, Inc.

Taira, D. A., Safran, D. G., Seto, T. B., Rogers, W. H., Kosinski, M., Ware, J. E., ... \& Tarlov, A. R. (1997). Asian-American Patient Ratings of Physician Primary Care Performance. Journal of general internal medicine, 12(4), 237-242.

Valentine, G. (2014). Social geographies: space and society. Routledge.

Williams, D. R. (1999). Race, socioeconomic status, and health the added effects of racism and discrimination. Annals of the New York Academy of Sciences, 896(1), 173-188.

Willems, S., De Maesschalck, S., Deveugele, M., Derese, A., \& De Maeseneer, J. (2005). Socioeconomic status of the patient and doctor-patient communication: does it make a difference? Patient education and counseling, 56(2), 139-146.

Whitehead, M., Dahlgren, G., \& Evans, T. (2001). Equity and health sector reforms: can lowincome countries escape the medical poverty trap?. The Lancet, 358(9284), 833-836. 